\title{
Preliminary Experiences of the Combined Midline-Splitting French Door Laminoplasty with Polyether Ether Ketone (PEEK) Plate for Cervical Spondylosis and OPLL
}

\author{
Chang Hyun $\mathrm{Oh}^{1^{*}}$, Gyu Yeul $\mathrm{Ji}^{2^{*}}$, Junseok W. Hur ${ }^{3}$, Won-Seok Choi ${ }^{3}$, \\ Dong Ah Shin ${ }^{2}$, Jang-Bo Lee ${ }^{3}$ \\ ${ }^{I}$ Department of Neurosurgery, Guro Teun Teun Hospital, Seoul, \\ ${ }^{2}$ Department of Neurosurgery, Yonsei University College of Medicine, Seoul, \\ ${ }^{3}$ Department of Neurosurgery, Anam Hospital, Korea University College of Medicine, Seoul, Korea
}

Objective: The purpose of this study was to evaluate the safety and efficacy of cervical midline-splitting French-door laminoplasty with a polyether ether ketone (PEEK) plate. The authors retrospectively analyzed the results of patients with cervical laminoplasty miniplate $\left(\right.$ MAXPACER $\left.^{\circledR}\right)$ without bone grafts in multilevel cervical stenosis.

Methods: Fifteen patients (13 males and 2 females, mean age 50.0 years (range 35-72)) with multilevel cervical stenosis (ossification of the posterior longitudinal ligament and cervical spondylotic myelopathy) underwent a combined surgery of midline-splitting French-door laminoplasty with or without mini plate. All 15 patients were followed for at least 12 months (mean follow-up 13.3 months) after surgery, and a retrospective review of the clinical, radiological and surgical data was conducted.

Results: The radiographic results showed a significant increase over the postoperative period in anterior-posterior diameter $(9.4 \pm 2.2 \mathrm{~cm}$ to $16.2 \pm 1.1 \mathrm{~cm})$, open angles in cervical lamina $\left(46.5 \pm 16.0^{\circ}\right.$ to $\left.77.2 \pm 13.1^{\circ}\right)$, and sectional volume of cervical central canal $\left(100.5 \pm 0.7 \mathrm{~cm}^{2}\right.$ to $\left.146.5 \pm 4.9 \mathrm{~cm}^{2}\right)(p<0.001)$. The sagittal alignment of the cervical spine was well preserved $\left(31.7 \pm 10.0^{\circ}\right.$ to $\left.31.2 \pm 7.6^{\circ}, p=0.877\right)$ during the follow-up period. The clinical results were successful, and there were no significant intraoperative complications except for screw displacement in two cases. The mini plate constructs did not fail during the 12 month follow-up period, and the decompression was maintained.

Conclusion: Despite the small cohort and short follow-up duration, the present study demonstrated that combined cervical expansive laminoplasty using the mini plate is an effective treatment for multilevel cervical stenosis.

Key Words: Cervical laminoplasty $\cdot$ French-door laminoplasty $\cdot$ PEEK plate $\cdot \mathrm{OPLL} \cdot$ Cervical spondylotic myelopathy

\section{INTRODUCTION}

Multilevel cervical canal stenosis causesd by the ossification of posterior longitudinal ligament (OPLL) or cervical spondylotic myelopathy (CSM) is common ${ }^{4,23,26)}$. Most patients are

- Received: January 5, 2015 - Revised: April 30, 2015

- Accepted: May 1, 2015

Corresponding Author: Jang-Bo Lee, MD, PhD

Department of Neurosurgery, Anam Hospital, Korea University College

of Medicine, Inchon-ro 73, Seongbuk-gu, Seoul 136-705, Korea

Tel: +82-2-920-5729, Fax: +82-2-929-0629

E-mail: jblee42@gmail.com

"These authors contributed equally to this project and should be considered as co-first authors.

"This study has not been presented in part elsewhere.

®This is an Open Access article distributed under the terms of the Creative

Commons Attribution Non-Commercial License (http://creativecommons.org/ licenses/by-nc/3.0/) which permits unrestricted non-commercial use, distribution, and reproduction in any medium, provided the original work is properly cited. asymptomatic, but those with severe spinal cord compression are predisposed to symptoms of cervical radiculopathy or myelopathy ${ }^{16,26}$. Surgical treatment is recommended when neurologic symptoms are severe. Cervical laminoplasty represents an effective technique in the treatment of multlevel cervical lesions. The technique enlarges of the canal which indirectly decompresses the spinal cord by allowing the dural sac to drift away from the spondylotic bars ${ }^{2,23}$. Several technical variations exist, such as the Z-plasty ${ }^{14)}$ or the open door technique $^{6}$. The French-door laminoplasty consists of a median lamina split followed by a lateral thinning and opening of both hemilaminae. The technique seems to provide satisfying and reliable long-term results in patients with OPLL and myelopathy due to cervical spondylosis and posterior thickening of the ligamentum flavum ${ }^{225)}$. Cervical expansive laminoplasty was originally carried out as a modified French-door laminoplasty using the spinous processes as spacers ${ }^{15}$. Since the design 
of classic open-door laminoplasty with the use of sutures, the procedure has been modified to reduce complications such as restenosis, axial symptoms, and segmental motor paralysis ${ }^{3,15)}$. With the development of surgical implants, various kinds of lamina spacers, such as the spinous processes, hydroxyapatite spacers, and Centerpiece ${ }^{\circledR}$ have been used to expand the narrowed spinal canal (Fig. 1) ${ }^{15}$. Each methods had its own advantages and disadvantages, but the recently developed laminoplasty fixation PEEK system with a biocompatible polymer securing the locking hinge of the plate without radiological artifacts has not been studied for its efficacy yet. The authors therefore began to use MAXPACER ${ }^{\circledR}$ (SeohanCare, GyeonggiDo, Korea, Fig. 2) as a lamina spacer with the French-door method, and compared the canal expansion rate among these methods.

\section{MATERIALS AND METHODS}

Between June and December 2012, combined surgery for multilevel cervical stenosis was performed by one neurosurgeon in a single university hospital. All patients were followed for at least 12 months after their operations. We performed a retrospective study of the 15 patients, analyzing the clinical and radiological results, including the difference in spinal canal areas between pre- and postoperative imaging.

The surgical procedure in the cases discussed here consisted of French-door laminoplasty with and without MAXPACER ${ }^{\circledR}$ L type (Fig. 2). Horizontal amputation of the spinous processes was performed and bilateral laminar exposure was carried out.
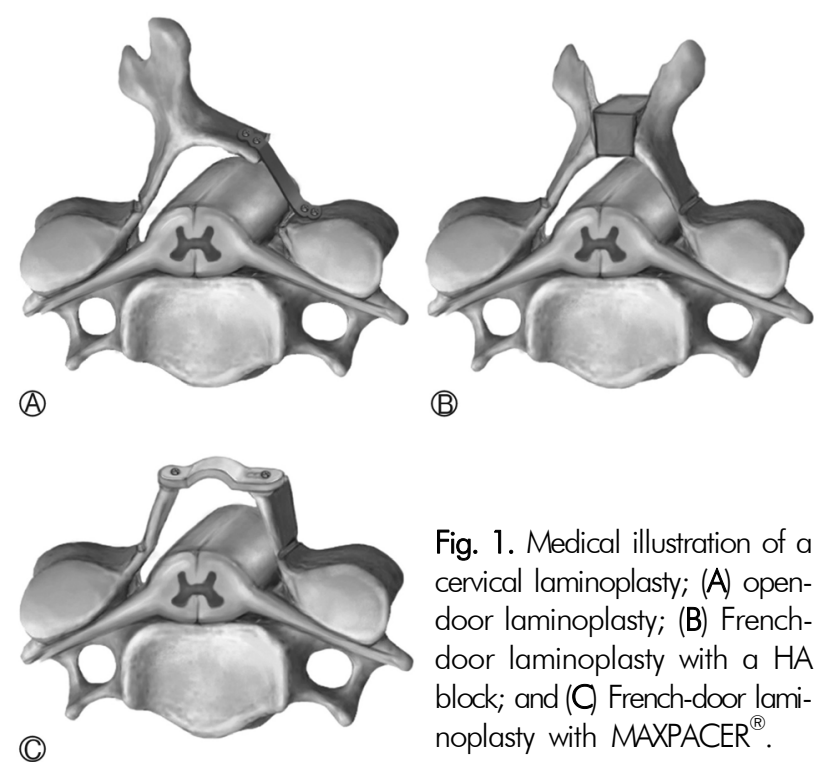

Fig. 1. Medical illustration of a cenvical laminoplasty; (A) opendoor laminoplasty; (B) Frenchdoor laminoplasty with a HA block; and (C) French-door laminoplasty with MAXPACER ${ }^{\circledR}$.
The upper half of spinous process was removed and applied to the gutter side after MAXPACER ${ }^{\circledR}$ was used for only bone fusion. Midline laminotomy was then performed with a drill, and lateral outer cortical bone drilling was done to facilitate elevation. During performing lateral outer cortical bone drilling, the surgeon found the lamina-facet junction, which was a landmark for drilling. It was important to drill just medial of the facet joint in order to have enough spinal canal area. Since the narrow drilling space can induce the lamina fracture when the lamina is elevated, adequate space was important to avoid fracturing the lamina. After drilling, the ligament flavum was split centrally and each lamina and ligamentum flavum was opened bilaterally until the lamina stood straight. After proper positioning of the laminae, MAXPACERs ${ }^{\circledR}$ were applied to the space between both laminae and secured by $8 \mathrm{~mm}$-sized titanium screws (Fig. 3). The decision of where to apply the MAXPACER ${ }^{\circledR}$ was determined when the canal

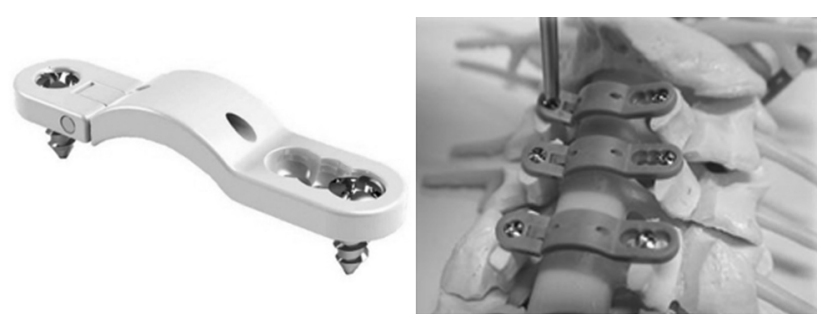

Fig. 2. Photograph of the cervical expansive laminoplasty device (MAXPACER $^{\circledR}$, SeohanCare, Gyeonggi-Do, Korea) and its application.

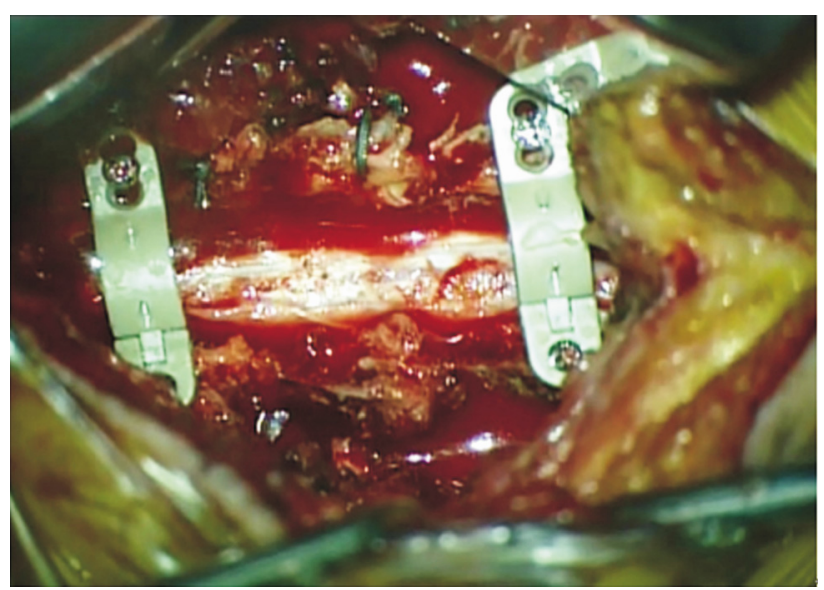

Fig. 3. Intraoperative photograph of patient with combined cervical expansive laminoplasty using the MAXPACER ${ }^{\circledR}$ with Frenchdoor laminoplasty at the C3 and C6 levels. Horizontal amputation of the spinous processes was performed and bilateral laminar exposure was carried out. The upper half of spinous process was removed and applied to the gutter side after MAXPACER ${ }^{\circledR}$ was used for only bone fusion. 
expansion was no longer sustained by the conventional Frenchdoor laminoplasty without the support of medical devices.

The authors used imaging programs (PACSPLUS PPW, medical standard, Korea) to measure the spinal canal area (Fig. 4). In all vertebrae, anatomical and radiological (magnetic resonance image, MRI) measurements were performed at the levels where MAXPACERs ${ }^{\circledR}$ were applied. Anterior-posterior diameter was the maximum distance between midpoint of the posterior border of vertebral body shadow and shadow of the spinolaminal junction of same vertebra ${ }^{12}$. The lamina opendoor angle was equal to the angle of two lines, one through both sides of the vertebral body crossing the transverse foramen posteriorly and the other connecting with the inside edge of the hinge side of the tangent of the lamina ${ }^{31}$. The C2-7 angle was measured by formal Cobb methods that verified the angle between the horizontal line of the C2 lower end plate and the horizontal line of the C7 lower end plate ${ }^{30)}$. Anatomical measurements were made by a single observer using an electronic caliper. The area of the preoperative spinal canal was defined as the region surrounded by the posterior border of the vertebral body and the inner border of the lamina, while that of the postoperative spinal canal was defined as the region surrounded by the posterior border of the vertebral body, the inner border of the lamina, and the inner border of a spacer. In cases of OPLL, OPLL was not excluded in the spinal canal
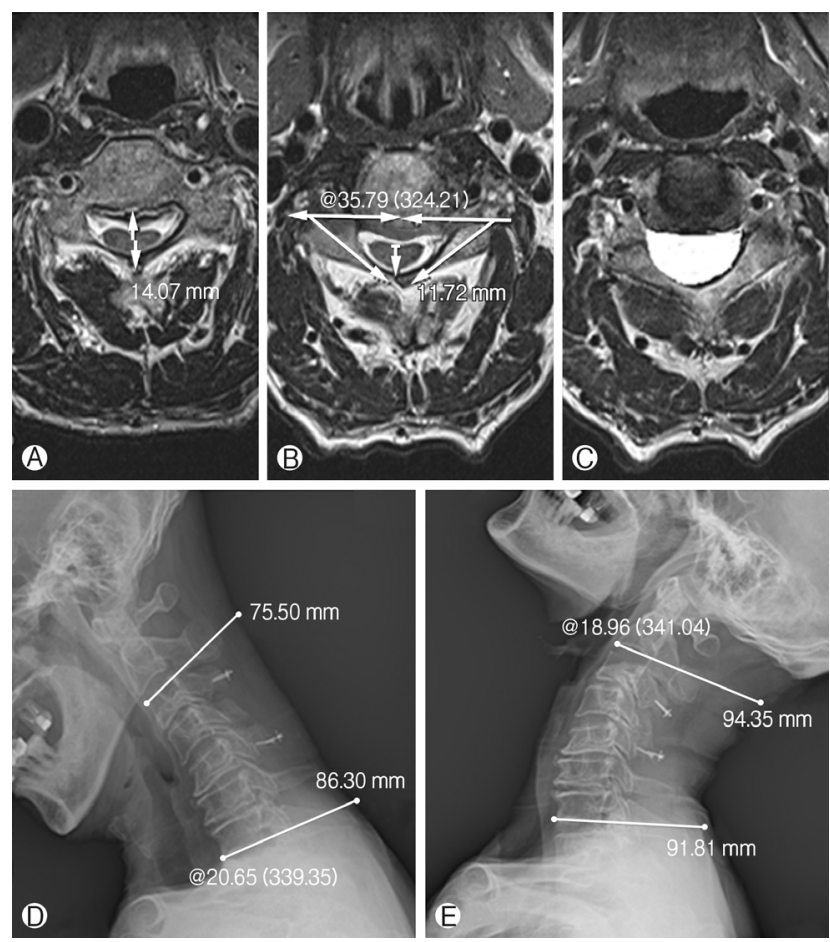

Fig. 4. Cervical measurements: (A) anterior-posterior diameter; (B) open angles; (C) 3D sectional volume; and (D) and (E) dynamic radiographs with Cobb's angle from $\mathrm{C} 2$ to $\mathrm{C} 7$. area to prevent overestimation of the expansion rate. We adjusted the images to be the same size among the same sections and compared the number of pixels in the spinal canal. The canal expansion rate was calculated by the increase in pixels from the preoperative to the postoperative images.

The severity of clinical symptoms was assessed using the various clinical score systems such as the visual analog scale (VAS), neck disability index (NDI), short-form 12 (SF-12), Japanese orthopedic association (JOA) score, and Odom's score. The preoperative and the one-year clinical scores were evaluated to determine whether there were significant differences. Persisting nuchal pain distributed over the posterior neck and shoulder pain in the area of the suspensory muscles were defined as axial symptoms. Preoperative neck and shoulder pain and subjective outcomes regarding axial symptoms were assessed using a VAS questionnaire, on a scale from ten points (extremely severe pain) to one point (almost no pain) at discharge, at 6 months and at the one-year follow-up. Pre- and post-operative VAS scores were evaluated to determine whether there were significant differences between the two groups.

The results are expressed as the mean \pm standard deviation. Paired Student t-test was used to assess the statistical differences of the demographic, clinical, and radiological data at each time point between the groups using SAS software for Windows (SAS Institute Inc., Cary, NC). A p $<0.050$ was considered as a significant statistical difference.

\section{RESULTS}

Among the 15 patients included in this retrospectively analyzed study, five patients had OPLL, nine had CSM, and one had a combined CSM and OPLL. A patient had a previous operative lesion with anterior cervical discectomy and fusion (ACDF). The mean age of the patients was 50.0 years (range 35-72). The male versus female ratio was 13:2 (Table 1). One patient underwent a laminoplasty C6 with MAXPACER ${ }^{\circledR}$ with a subtotal laminectomy C5 and C7. Another patient had a laminoplasty C2-6 with MAXPACER ${ }^{\circledR}$. Eight patients underwent laminoplasties of C3-6 with MAXPACER ${ }^{\circledR}$. Four patients had laminoplasties of C4-6 with MAXPACER ${ }^{\circledR}$ One patient underwent a laminoplasty C5-7 with MAXPACER ${ }^{\circledR}$. Cervical French-door laminoplasties with and without MAXPACER ${ }^{\circledR}$ were applied in all patients with 53 levels. MAXPACERs ${ }^{\circledR}$ were used in 25 levels, and an average 1.67 levels of MAXPACER ${ }^{\circledR}$ were applied. The most commonly MAXPACER ${ }^{\circledR}$ applied cervical level was C6 $(n=13)$ followed by C3 $(n=5), C 4(n=3)$, C5 $(n=3)$, and C2 $(n=1)$.

Although this data included only a limited number of cases $(n=15)$, the most of radiological outcomes after applying 
MAXPACER $^{\circledR}$ were significantly increased compared to the preoperative baseline. Anterior-posterior diameter $(\mathrm{mm})$ was grossly increased from $9.4 \pm 2.2$ in preoperative patients to $16.2 \pm 1.1$ in the postoperative status $(p<0.001$, Fig. 5). Accordingly, the application level of MAXPACER ${ }^{\circledR}$, all mean anterior-posterior diameters $(\mathrm{mm})$ were increased in the postoperative compared to preoperative status (7.6 to 10.8 in C2, 8.3 to 16.1 in $\mathrm{C} 3,8.9$ to 15.4 in $\mathrm{C} 4,9.0$ to 14.8 in $\mathrm{C}$, and 10.1 to 17.2 in C6). The statistical differences were only observed in $\mathrm{C} 5$ and $\mathrm{C} 6$ due the small number of cases (a case in C2, 5 in C3, 3 in C4 and C5, and 13 in C6). The open angles before and after laminoplaty using MAXPACER ${ }^{\circledR}$ were significantly increased except at the level of $\mathrm{C} 5$, as is presented in Fig. 5; from $46.5^{\circ}$ to $77.2^{\circ}$ in all cervical levels $(n=50$, $\mathrm{p}<0.001), 43.7^{\circ}$ to $78.6^{\circ}$ in $\mathrm{C} 2$ ( $\left.\mathrm{n}=2, \mathrm{p}=0.013\right), 38.7^{\circ}$ to $71.1^{\circ}$ in $\mathrm{C} 3(\mathrm{n}=10, \mathrm{p}<0.001), 51.1^{\circ}$ to $84.2^{\circ}$ in $\mathrm{C} 4(\mathrm{n}=6, \mathrm{p}=0.012)$, $51.8^{\circ}$ to $82.0^{\circ}$ in $\mathrm{C} 5(\mathrm{n}=6, \mathrm{p}=0.110)$, and $47.5^{\circ}$ to $76.7^{\circ}$ in $\mathrm{C} 6(\mathrm{n}=26, \mathrm{p}<0.001)$. The $\mathrm{C} 2-7$ angle by Cobb methods were preserved after laminoplaty using MAXPACER ${ }^{\circledR}$ as $31.7 \pm 10.0^{\circ}$ in preoperative and $31.2 \pm 7.6^{\circ}$ in final postoperative followup $(p=0.645$, Fig. 5). The expansion area of the spinal canal was significantly increased from $100.5 \pm 0.7 \mathrm{~cm}^{2}$ preoperatively to $146.5 \pm 4.9 \mathrm{~cm}^{2}$ postoperative 12 months ( $<<0.001$, Fig. 5 ).

Postoperative clinical scores were excellent compared to the preoperative status in terms of VAS (Neck), VAS (Arm), NDI, and JOA (Fig. 6). The VAS for neck and arm pain decreased from 3.1 and 3.8 in the preoperative period to 0.6 and 1.41 postoperatively (both $\mathrm{p}<0.001$ ), respectively. Preoperative NDI was $18.5 \pm 5.6$ and decreased to $8.6 \pm 4.5$ in the postoperative period $(\mathrm{p}<0.001)$, and JOA was also improved from $11.9 \pm 4.2$ to $14.3 \pm 2.1$ ( $\mathrm{p}=0.023)$. The SF-12 for physical and mental health composite scale (PCS and MCS) were shown as $24.4 \pm 4.2$ and $27.9 \pm 3.5$ at postoperatively. Odom's score showed excellent results in five cases, good result in six cases, and fair results in four cases.

The MAXPACER ${ }^{\circledR}$ constructs did not fail during the 12month follow-up period, and the decompression was maintained. The only observed complication related to the medical device was the displacement of screws in two cases, which occurred during the surgical procedures (Fig. 7). Serious compli cations such as instability and kyphosis did not develop in any cases.
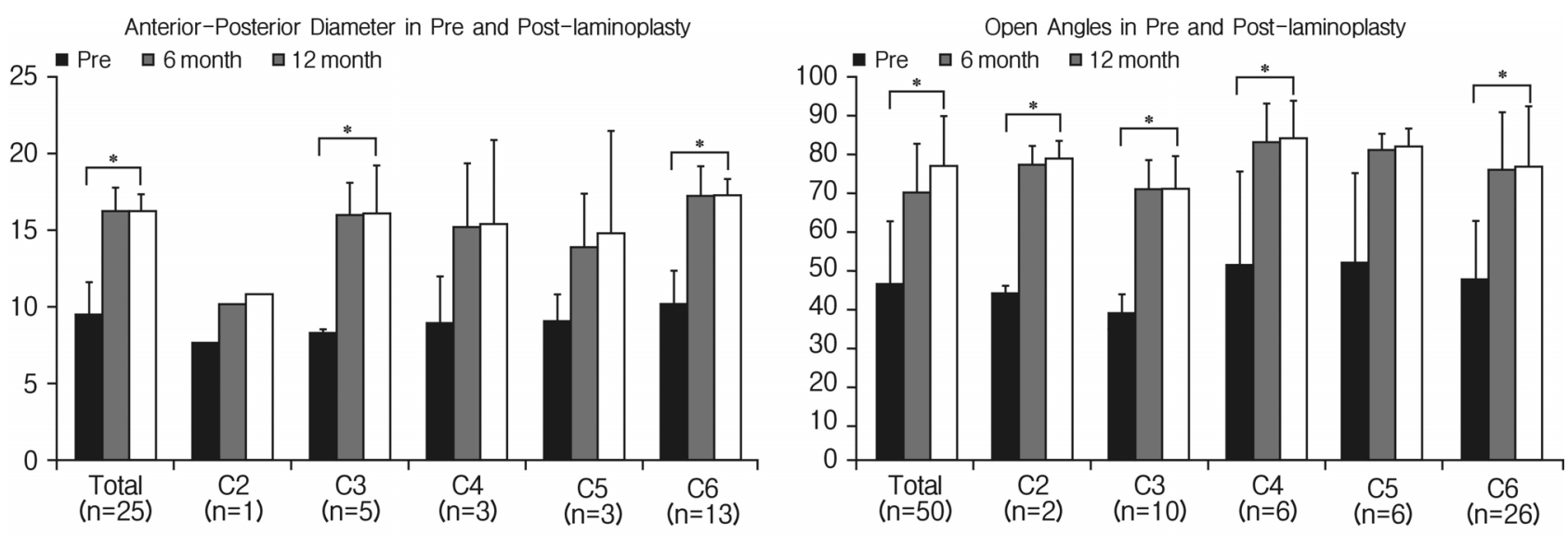

Cobb Angle
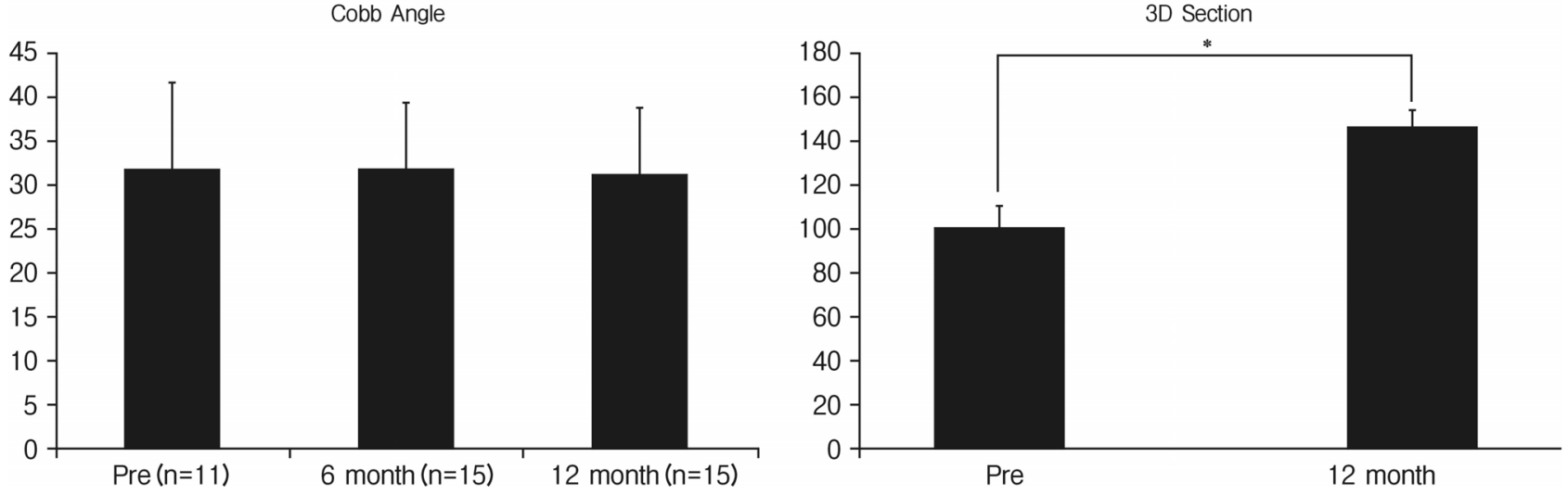

Fig. 5. The change of anterior-posterior diameter, open angle, C2-7 angle by Cobb methods, and expansion area of the spinal canal before and after cervical laminoplasty with MAXPACER ${ }^{\circledR}$ 

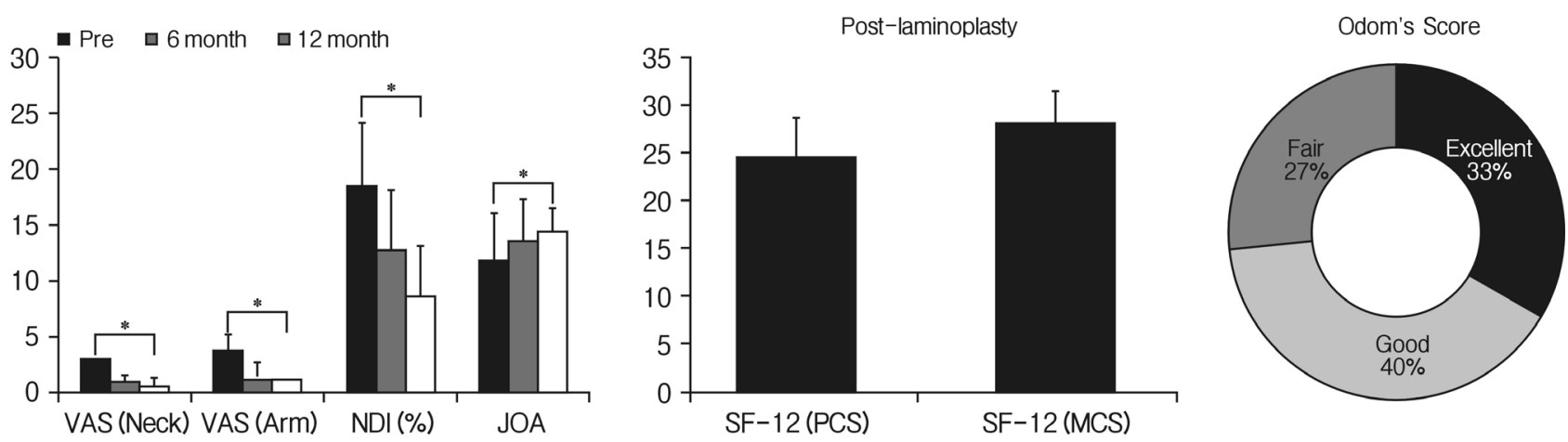

Fig. 6. The change of clinical parameters (VAS, NDI, JOA, SF-12, and Odom's score) before and after cervical laminoplasty with MAXPACER ${ }^{\circledR}$.

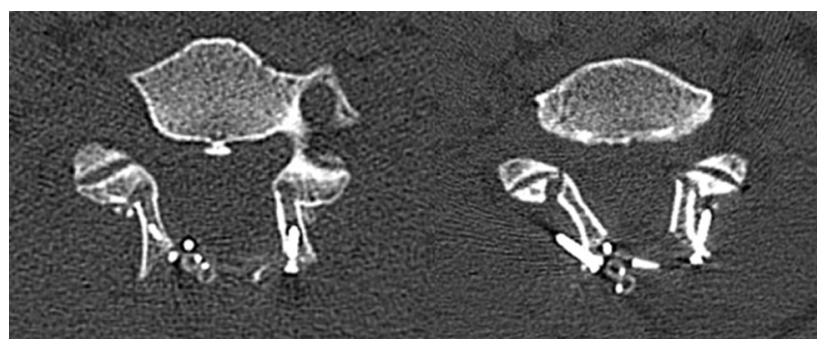

Fig. 7. Screw displacement was observed in two cases during the follow-up period.

\section{DISCUSSION}

In conditions such as degenerative cervical spondylosis, herniated cervical disc and OPLL, laminoplasty is considered as the one of the most useful surgical treatments ${ }^{4,23,26}$. Numerous studies have reported satisfactory surgical outcomes with laminoplasty, and many technical modifications have been made to the procedure ${ }^{13-15,21,24,25)}$. Generally speaking, there are two types of laminoplasty methods. The first is the open-door method and the other is the French-door method. French-door laminoplasty was originally devised by Kurokawa ${ }^{19,23,28)}$. In this procedure, the expansion of the spinal canal and preservation of the posterior structures for stability of the cervical spine are important ${ }^{18)}$. French-door laminoplasty allows for easy placement of spacers and performance of bilateral decompression $^{1,8-10,32)}$. And, French-door laminoplasty has shown superior clinical and radiological outcomes compared to opendoor laminoplasty, in addition to preserving cervical muscle strength after laminoplasty ${ }^{17,20,22)}$. Both open-door and Frenchdoor laminoplasties might be similarly effective in decompression of the spinal cord; however, axial pain was improved more and the cervical lordotic angle was increased more in the French-door group after surgery ${ }^{22}$.

French-door laminoplasty can be divided into two methods, including the conventional spinous process-splitting method and the lamina-splitting method ${ }^{27)}$. Because the spacers are inserted between the split laminae, the desired enlargement of the spinal canal can be obtained simply by choosing a spacer of the appropriate width ${ }^{27}$. Spacers may be less stable in the lamina-splitting method, because the contact area between the laminae and the spacers is less than that between the spinous processes and the spacers in the spinous process-splitting method. Sufficient stability could be obtained by several techniques, including the 4-point suture. Spacer fixation with screws is advantageous because of its relative ease, the speed of the procedure, and strength to pull-out ${ }^{27}$. Herein, the MAXPACER ${ }^{\circledR}$ was secured by $8 \mathrm{~mm}$ sized titanium screws between both laminae.

Few studies compare the spinal canal area among the different types of laminoplasty. Hirabayashi et al. reported that the open-door laminoplasty with hydroxyapatite resulted in a significantly larger expansion ratio than the double-door laminoplasty ${ }^{6}$. In the study by Kim et al., they compared the amount of canal expansion among the three major types of implants used in laminoplasty ${ }^{15}$. The major finding to come from this comparison is that box-shaped laminoplasty with miniplates allows the widest canal expansion of the three implant types. The canal expansion rate with miniplates was 76.5 $\%$, while that of hydroxyapatite was $49.8 \%$, and that achieved with Centerpiece was 50.6\%. In addition, there were no reported complications associated with the miniplates. We obtained similar results in our study. Anterior-posterior diameter (9.4 \pm 2.2 to $16.2 \pm 1.1 \mathrm{~mm}$ ), the open angles $\left(46.5^{\circ}\right.$ to $\left.77.2^{\circ}\right)$, and the expansion area of the spinal canal $(100.5 \pm 0.7$ to $146.5 \pm$ $4.9 \mathrm{~cm}^{2}$ ) were significantly increased postoperatively by using the MAXPACER ${ }^{\circledR}$. Indeed, the C2-7 angle by Cobb methods was preserved after laminoplaty using MAXPACER ${ }^{\circledR}(31.7 \pm$ $10.0^{\circ}$ to $31.2 \pm 7.6^{\circ}$ ). The clinical results were also excellent in term of VAS (Neck), VAS (Arm), NDI, JOA, and SF-12 (PCS and MCS). 
But, the relationship between the degree of spinal canal expansion and clinical results after laminoplasty remains unclear. It was noted that spinal cord function can be regained with a minimal degree of enlargement of the spinal canal and that $4 \mathrm{~mm}$ enlargement of the spinal canal is generally ideal ${ }^{11}$. It has also been reported that patients with a postoperative cross-sectional area of $>160 \mathrm{~mm}^{2}$ achieve a better outcome ${ }^{5}$. It was believed that the optimal enlargement of the stenotic canal by laminoplasty is greater than $4-5 \mathrm{~mm}$ in the sagittal diameter $^{7}$. However, although the spinal canal area can be greatly increased during laminoplasty, excessive opening of the lamina may cause problems. The kinking of the nerve root induced by maximal decompression might be related to the occurrence of postoperative $\mathrm{C} 5$ nerve root palsy and radiculopathy ${ }^{29)}$. Excessive opening also creates epidural space and can lead to the formation of more epidural scar tissue than expected $^{8,10,15)}$.

Device-related complications were very low in using the MAXPACER $^{\circledR}$, as our study showed only two cases with screw malposition (4\% among total 50 screws in MAXPACER ${ }^{\circledR}$ ). This complication was occurred during the operation while the surgeon was learning the technique. The screw displacements did not disturb the clinical outcomes in this retrospective study. In summary of this study and the literatures, MAXPACER ${ }^{\circledR}$ showed several advantage compared to conventional laminoplasty such as excellent surgically accessibility with easy handling $^{27}$, sufficient increase of spinal canal volume ${ }^{15,27}$, reasonable clinical outcome ${ }^{27)}$, very low chance of intraoperative device failure with the device stability after even though device mal-positioned, and the consistency of device after plate implanted. Therefore, combined French-door laminopalsty using MAXPACER $^{\circledast}$ is a useful and safe surgical technique, as long as the surgeon assures that the screws are properly positioned in the posterior laminaes.

Despite our findings, this study had several limitations. In particular, the number of patients was small and the follow-up period was too short to allow a generalization of our results. Indeed, we only performed an observational study and did not compare our results with those of alternative techniques. So, additional study is required to compare the French-door laminoplasty with the medical spacer in cases with identical operative indications.

\section{CONCLUSION}

Combined cervical expansive laminoplasty using a MAXPACER ${ }^{\circledR}$ with French-door laminoplasty is an effective treatment for multi-level cervical stenosis. Despite the small cohort and short follow-up duration in our study, future studies will be able to further confirm our findings.

\section{ACKNOWLEDGMENT}

This study is External funding was received from SeohanCare (Manufacture of MAXPACER $^{\circledR}$, Gyeonggi-do, Korea), and the authors declare that they have no proprietary, commercial, or financial interests that could be construed to have in appropriately influenced this study.

\section{REFERENCES}

1. Asano T, Tsuzuki N: Surgical management of ossification of posterior longitudinal ligament in Schmidek $\mathrm{HH}$, Sweet $\mathrm{WH}$ (eds): Operative Neurosurgical Techniques. Indications, Methods and Results, ed 3. Philadelphia: W.B. Saunders, Vol 2, pp 18251828, 1995

2. Charles YP, Schuller S, Sfeir G, Steib JP: French door laminoplasty for cervical spondylotic myelopathy. Eur Spine J 22:21232125, 2013

3. Chen G, Luo Z, Nalajala B, Liu T, Yang H: Expansive open-door laminoplasty with titanium miniplate versus sutures. Orthopedics 35:e543-548, 2012

4. Chen HC, Chang MC, Yu WK, Wang ST, Liu CL, Chen TH: Lateral mass anchoring screws for cervical laminopasty: preliminary report of a novel technique. J Spinal Disord Tech 21: 387-392, 2008

5. Hamburger C, Büttner A, Uhl E: The cross-sectional area of the cervical spinal canal in patients with cervical spondylotic myelopathy: Correlation of preoperative and postoperative area with clinical symptoms. Spine 22:1990-1994, 1997

6. Hirabayashi K, Tomita Y, Chiba K: Expansive laminoplasty for myelopathy in ossification of the longitudinal ligament. Clin Orthop Relat Res 359:35-48, 1999

7. Hirabayashi K, Watanabe K, Wakano K, Suzuki N, Satomi K, Ishii Y: Expansive open-door laminoplasty for cervical spinal stenotic myelopathy. Spine 8:693-699, 1983

8. Hirabayashi S, Koshizuka Y: New method for measuring area of spinal canal after double-door laminoplasty. J Orthop Sci 4: 78-82, 1999

9. Hirabayashi S, Kumano K: Development of a new spacer well adapted to split spinous process in double-door laminoplasty. Seikeigeka 46:110-112, 1995

10. Hirabayashi S, Yamada H, Motosuneya T, Watanabe Y, Miura $\mathrm{M}$, Sakai $\mathrm{H}$, et al: Comparison of enlargement of the spinal canal after cervical laminoplasty: open-door type and doubledoor type. Eur Spine J 19:1690-1694, 2010

11. Itoh T, Tsuji H: Technical improvements and results of laminoplasty for compressive myelopathy in the cervical spine. Spine 10:729-736, 1985

12. Kathole MA, Joshi RA, Herekar NG, Jadhav SS: Dimensions of cervical spinal canal and vertebrae and their relevance in clinical practice. Int J Recent Trends Sci Tech 3:54-58, 2012

13. Kawaguchi Y, Kanamori M, Ishihara H, Ohmori K, Nakamura 
H, Kimura T: Minimum 10-year followup after en bloc cervical laminoplasty. Clin Orthop Relat Res 411:129-139, 2003

14. Kawai S, Sunago K, Doi K, Saika M, Taguchi T: Cervical laminoplasty (Hattori's method). Procedure and follow-up results. Spine 13:1245-1250, 1998

15. Kim JH, Zhang HY, Park YM: Cervical expansive laminoplasty with $90^{\circ}$ box-shape double door method. Korean J Spine 9:193196, 2012

16. Kim YS, Chin DK, Cho YE, Jin BH, Yoon YS, Park JP, et al: Surgical treatment for ossification of the posterior longitudinal ligament of the cervical spine. J Korean Neurosurg Soc 26: 1237-1245, 1997

17. Lee DG, Lee SH, Park SJ, Kim ES, Chung SS, Lee CS, et al: Comparison of surgical outcomes after cervical laminoplasty: open-door technique versus French-door technique. J Spinal Disord Tech 26:E198-203, 2013

18. Machino M, Yukawa Y, Hida T, Ito K, Nakashima H, Kanbara $\mathrm{S}$, et al: Modified double-door laminoplasty in managing multilevel cervical spondylotic myelopathy: surgical outcome in 520 patients and technique description. J Spinal Disord Tech 26: 135-140, 2013

19. Matsuda Y, Shibata T, Oki S, Kawatani Y, Mashima N, Oishi $\mathrm{H}$ : Outcomes of surgical treatment for cervical myelopathy in patients more than 75 years of age. Spine 24:529-534, 1999

20. Nakama S, Nitanai K, Oohashi Y, Endo T, Hoshino Y: Cervical muscle strength after laminoplasty. J Orthop Sci 8:36-40, 2003

21. Ogawa Y, Toyama Y, Chiba K, Matsumoto M, Nakamura M, Takaishi $\mathrm{H}$, et al: Long-term results of expansive open-door laminoplasty for ossification of the posterior longitudinal ligament of the cervical spine. J Neurosurg Spine 1:168-174, 2004

22. Okada M, Minamide A, Endo T, Yoshida M, Kawakami M, Ando $\mathrm{M}$, et al: A prospective randomized study of clinical outcomes in patients with cervical compressive myelopathy treated with open-door or French-door laminoplasty. Spine 34:11191126, 2009
23. Ratliff JK, Cooper PR: Cervical laminoplasty: a critical review. J Neurosurg Spine 98:230-238, 2003

24. Satomi K, Nishu Y, Kohno T, Hirabayashi K: Long-term follow up studies of open-door expansive laminoplasty for cervical stenotic myelopathy. Spine 19:507-510, 1994

25. Seichi A, Takeshita K, Ohnishi I: Long-term results of double door laminoplasty for cervical stenotic myelopathy. Spine 26: 479-487, 2001

26. Son S, Lee SG, Park CW, Kim WK: Combined open door laminoplasty with unilateral screw fixation for unstable multi-level cervical stenosis: a preliminary report. J Korean Neurosurg Soc 53:83-88, 2013

27. Takayasu M, Takagi T, Nishizawa T, Osuka K, Nakajima T, Yoshida J: Bilateral open-door cervical expansive laminoplasty with hydroxyapatite spacers and titanium screws. J Neurosurg 96:22-28, 2002

28. Tomita K, Kawahara N, Toribatake Y, Heller JG: Expansive midline T-saw laminoplasty (modified spinous process-splitting) for the management of cervical myelopathy. Spine 23:32-37, 1998

29. Uematsu Y, Tokuhashi Y, Matsuzaki H: Radiculopathy after laminoplasty of the cervical spine. Spine 23:2057-2062, 1998

30. Vialle R, Levassor N, Rillardon L, Templier A, Skalli W, Guigui $\mathrm{P}$ : Radiographic analysis of the sagittal alignment and balance of the spine in asymptomatic subjects. J Bone Joint Surg Am 87:260-267, 2005

31. Zhang H, Lu S, Sun T, Yadav SK: Effect of lamina open angles in expansion open-door laminoplasty on the clinical results in treating cervical spondylotic myelopathy. J Spinal Disord Tech: 89-94, 2015

32. Zhang J, Hirabayashi S, Saiki K, Sakai H: Effectiveness of multiple-level decompression in laminoplasty and simultaneous C1 laminectomy for patients with cervical myelopathy. Eur Spine J 15:1367-1374, 2006 